\title{
Increasing great toe pain in a patient with soft tissue swelling and nail enlargement
}

\author{
Kensaku Yamaga • Takeshi Minamizaki • \\ Toshiyuki Dokai $\cdot$ Takahide Kikkawa $•$ Haruhiko Yoshida
}

Published online: 11 February 2015

(C) ISS 2015

\section{Question}

A 16-year-old boy presented with pain and soft tissue swelling of his right great toe. A clinical photograph is shown (Fig. 1). Radiography, CT, and MRI examinations were performed (Fig. 2, 3, and 4). A photomicrograph of the lesion is shown (Fig. 5).

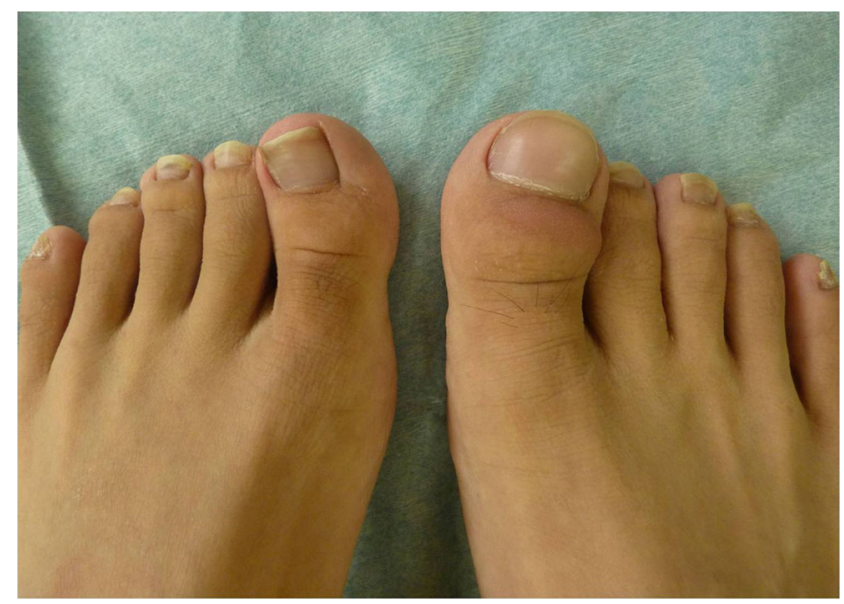

Fig. 1 Clinical photograph

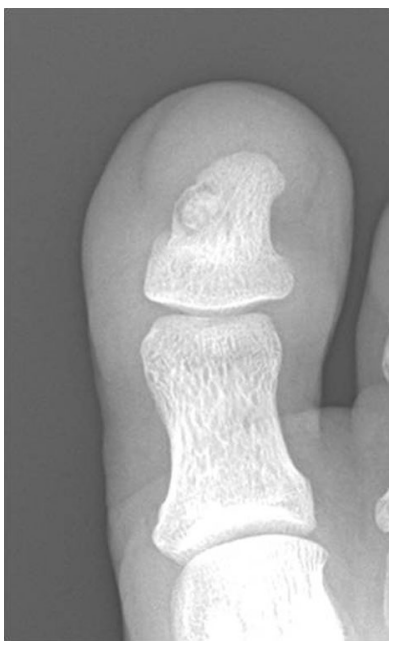

Fig. 2 Radiograph of the great toe
The diagnosis can be found at doi: 10.1007/s00256-015-2110-Z

K. Yamaga · T. Minamizaki · T. Dokai · T. Kikkawa

Department of Orthopaedic Surgery, Yonago Medical Center,

Yonago, Japan

\section{H. Yoshida}

Department of Pathology, Yonago Medical Center, Yonago, Japan

Present Address:

K. Yamaga $(\bowtie)$

Department of Orthopaedic Surgery, Faculty of Medicine, Tottori University, 36-1 Nishi-cho, Yonago, Tottori 683-8504, Japan e-mail: y10142527@gmail.com 


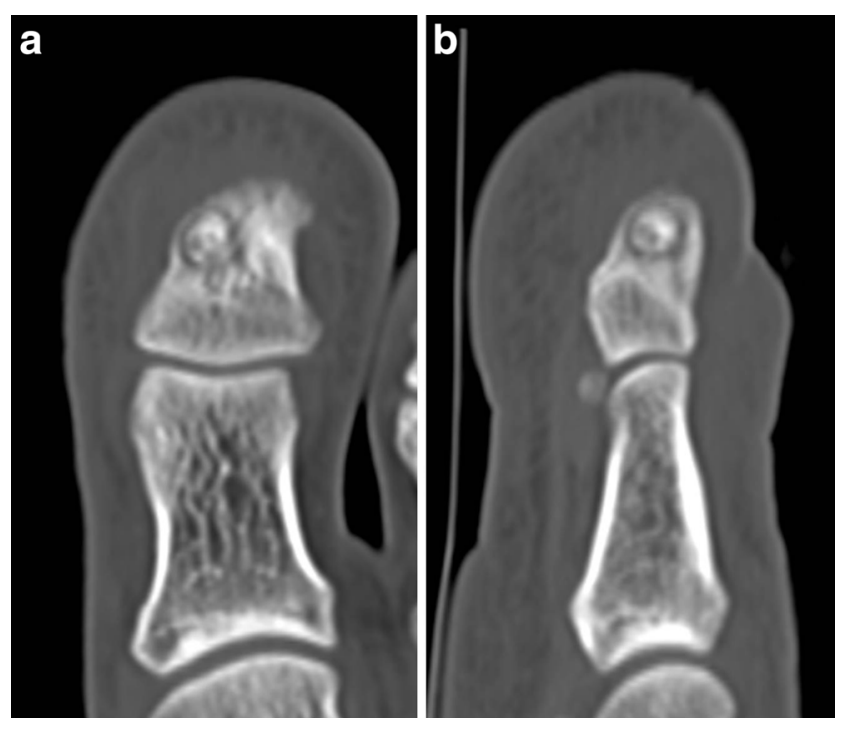

Fig. 3 Representative CT. a Coronal section. b Sagittal section

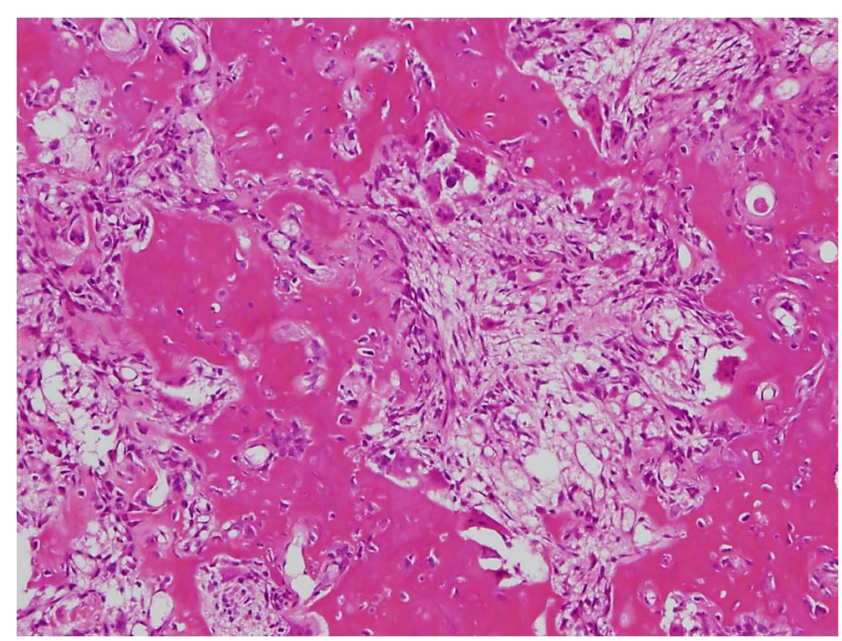

Fig. 5 Histological photograph
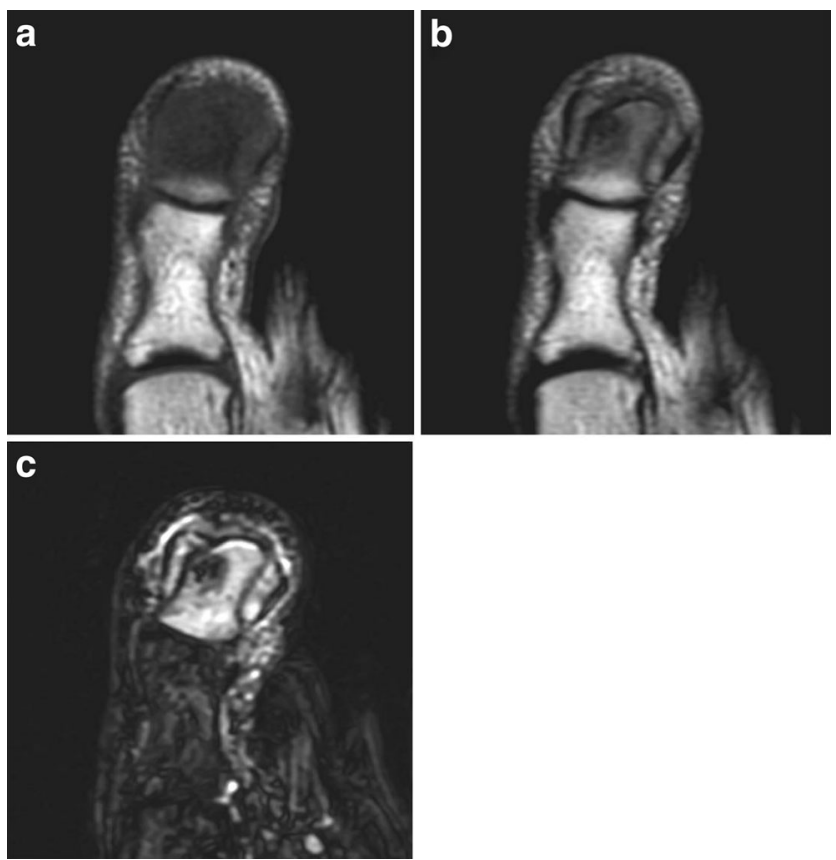

Fig. 4 Representative coronal MRI. a T1-weighted image. b T2weighted image. c Short-tau inversion recovery image 